\title{
Seismic response analysis on the prestressed concrete converting truss structure
}

\author{
Ying Zhang ${ }^{1, a}$, Xin Wei ${ }^{2, b}$, Yunmeng Chen ${ }^{2, c}$ \\ ${ }^{1}$ College of Civil Engineering, Heilongjiang Polytechnic , Harbin,150001,China \\ ${ }^{2}$ College of Aerospace and Civil Engineering, Harbin Engineering University, Harbin,150001, China

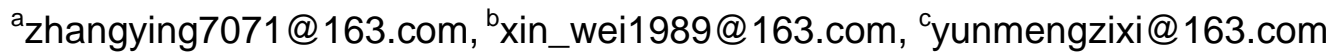

Keywords: Prestressed concrete converting truss; Mode-superposition response spectrum; Dynamic time history response.

Abstract: On the basis of simulating finite element model that according to an actual engineering, the paper uses mode-superposition response spectrum for the calculation of horizontal and vertical seismic actions. In addition, to obtain dynamic time history response of the prestressed concrete conversion truss structure under the seismic action, the paper chooses appropriate ground motion records to simulate the finite element mode via sap2000 as the supplement calculation.

\section{Project profile}

This project is Daqing iron man- Jinxi Wang memorial hall. The plane rectangular part of one-layer axis size is $112.95 \mathrm{~m} \times 72.94 \mathrm{~m}$, the plane rectangular part of six-layer axis size is $42.38 \mathrm{~m} \times 72.94 \mathrm{~m}$. The first layer sets a multi-function hall with span of $30 \mathrm{~m}$.It uses prestressed well-shaped beam structure, the span on both sides is over $18 \mathrm{~m}$ and use prestressed concrete beams. Besides, the middle hall uses prestressed concrete hollow slab structure. Due to the span between the axis $\mathrm{N}$ and $\mathrm{P}$ is up to $30 \mathrm{~m}$, the middle part of the framework uses different concrete structure, but cracks width is difficult to meet the specification requirements. Therefore, this part uses large-span prestressed concrete conversion truss structure which is shown in Fig.1. Height of truss is 4.5m, concrete grade is C40, the low relaxation prestressed reinforcement $\Phi$ s15.2 steel strand, non-prestressed longitudinal reinforcement is HRB400. The original design of this project is simulated and analysis calculated by PKPM series software, using PMCAD to build the mode of the whole building which is shown in Fig.2.

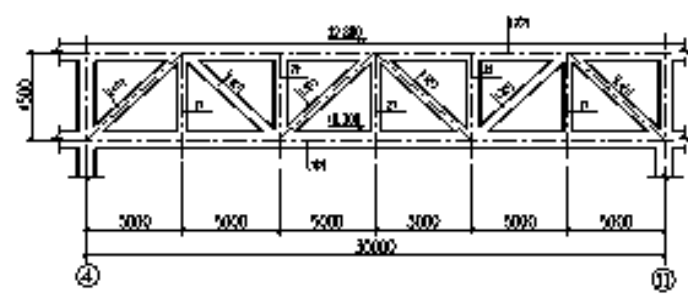

Fig.1.truss structure layout

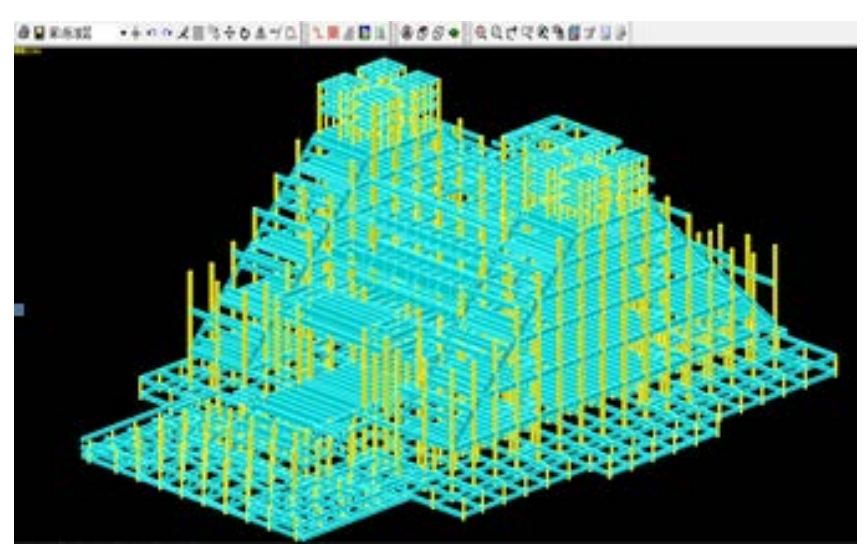

Fig.2.original structure space model

\section{Structural mode-superposition response spectrum analysis}

The paper uses vibration mode decomposition response spectrum method to analyze the response of the structure under seismic action. Firstly, the paper selects the internal force, control point displacements of important robs as the index and then investigate the structure seismic response. The node number is shown in Fig.3.4. 


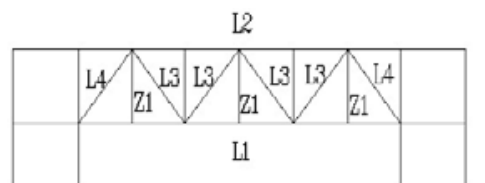

Fig.3.Truss bar number

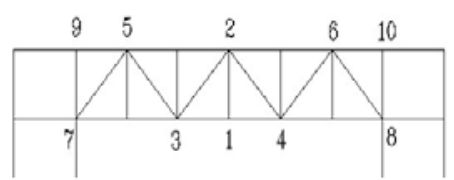

Fig.4.Truss control point number

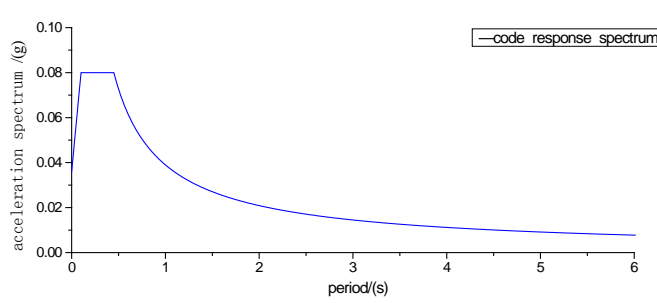

Fig.5.Response spectrum of earthquake influence coefficient curve (damping ratio, 0.05)

Basic parameters determination. The designing service life of this project is one hundred years. According to the seismic design code (GB50011-2001), the building importance for categories is one.

Calculation and analysis of earthquake response spectrum. During the response spectrum analysis, the response spectrum incentive condition of the $\mathrm{X}$ direction is shown in figure 5.After the modal analysis, spectrum analysis, modal expansion and modal combination, the paper gets the final result of seismic response of the structure's internal force and deformation that is shown in Tab.1,2,3.

Tab.1.inner force calculation results of key member (horizontal earthquake)

\begin{tabular}{c|c|c|c|c|c|c|c}
\hline bar & $\begin{array}{c}\text { The } \\
\text { middle } \\
\text { section } \\
\text { of L1 }\end{array}$ & $\begin{array}{c}\text { ends of } \\
\text { L1 }\end{array}$ & L2 & L3left & L3right & L4 & Z1 \\
\hline $\begin{array}{c}\text { Bending moment } \\
(\mathrm{N} \cdot \mathrm{m})\end{array}$ & 109 & 20 & 23.19 & 0 & 0 & 0 & 0 \\
\hline Axial force (N) & 109 & 156 & 171 & 891 & 891 & 1021 & 0 \\
\hline
\end{tabular}

Tab.2.key nodal displacement calculation results (horizontal earthquake)

\begin{tabular}{c|c|c|c|c|c|c}
\hline $\begin{array}{c}\text { vertical } \\
\text { displacement } \\
(\mathrm{mm})\end{array}$ & 27.01 & 28.44 & 26.89 & 26.78 & 28.64 & $\begin{array}{c}\text { vertical } \\
\text { displacement } \\
(\mathrm{mm})\end{array}$ \\
\hline node & 1 & 2 & 3 & 4 & 5 & node \\
\hline
\end{tabular}

Tab.3.top 15 order modal of the model

\begin{tabular}{c|c|c|c|c|c|c|c|c}
\hline $\begin{array}{c}\text { Order } \\
\text { number }\end{array}$ & $\begin{array}{c}\text { Natural } \\
\text { vibration } \\
\text { period (s) }\end{array}$ & $\begin{array}{c}\text { Natural } \\
\text { frequency of } \\
\text { vibration } \\
(\mathrm{Hz})\end{array}$ & $\begin{array}{c}\text { Order } \\
\text { numbe }\end{array}$ & $\begin{array}{c}\text { Natural } \\
\text { vibration } \\
\text { period (s) }\end{array}$ & $\begin{array}{c}\text { Natural } \\
\text { frequency of } \\
\text { vibration(Hz) }\end{array}$ & $\begin{array}{c}\text { Order } \\
\text { numbe }\end{array}$ & $\begin{array}{c}\text { Natural } \\
\text { vibration } \\
\text { period (s) }\end{array}$ & $\begin{array}{c}\text { Natural } \\
\text { frequency of } \\
\text { vibration( Hz) }\end{array}$ \\
\hline 1 & 1.7928 & 0.5578 & 6 & 0.0728 & 13.7436 & 11 & 0.0423 & 23.6224 \\
\hline 2 & 0.3171 & 3.1536 & 7 & 0.0640 & 15.6183 & 12 & 0.0422 & 23.6907 \\
\hline 3 & 0.1636 & 6.1145 & 8 & 0.0499 & 20.0422 & 13 & 0.0402 & 24.900 \\
\hline 5 & 0.1417 & 7.0593 & 9 & 0.0457 & 21.8914 & 14 & 0.0396 & 25.2622 \\
\hline
\end{tabular}

\section{Structure analysis of SAP2000 finite element calculation}

The beam, column and other main parts of the structure use the displacement and acceleration time history curves of the reference point in the program. Beam-column node is consolidated in the model, and the bottom of the frame column and the foundation constraints are simulated with fixed edge .Model is shown in Fig. 6. 


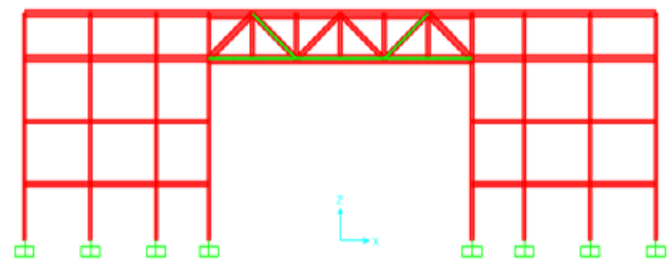

Fig. 6 .Sap2000 finite element model

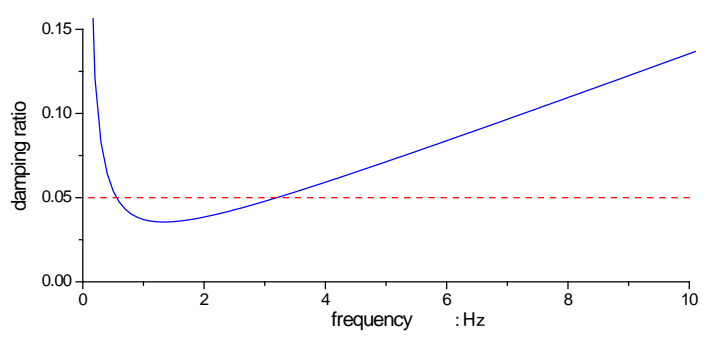

Fig.7. Structural damping ratio curve

Application of prestressing force. There are two ways to simulate prestress in SAP2000. One is considering the prestress as an equivalent load, another is the real physical reinforcement method. That is to take it as the independent units with stiffness and mass. The layout method of prestressed reinforcement is generally divided into three kinds: polygonal-shape, parabola-shape and linear type. Polygonal-shaped prestressed tendons are arranged in the bottom chord and parts of compressive brace. The constant load, live load and the time history analysis results considering the 7 degrees of horizontal seismic action are combined as Eq. 1.

$$
S=\gamma_{G} S_{G E}+\gamma_{E h} S_{E h k}+\gamma_{E v} S_{E v k}
$$

The modal analysis. Modal analysis is used to determine the natural frequencies and mode shapes of the structure, it is a foundation of transient dynamic time history analysis and spectrum analysis. The natural vibration characteristic of the structure is an important indicator of measuring whether the mass and stiffness is matched reasonably or not. Moreover, whether the finite element model reflects the actual dynamic of structure correctly can be judged by viewing basic mode of the model established. The Rayleigh damping matrix is just the linear combination of the mass matrix [M]and the stiffness matrix [K].In addition, it is orthogonal vibration mode (although this feature no longer exists in nonlinear analysis).Its expression is showed as Eq. 2 and Eq. 3. Fig. 8 and Fig. 9

$$
\begin{aligned}
& {[C]=a_{0}[M]+b_{0}[K]} \\
& \left\{\begin{array}{l}
a_{0} \\
b_{0}
\end{array}\right\}=\frac{2 \omega_{m} \omega_{n}}{\omega_{n}^{2}-\omega_{m}^{2}}\left[\begin{array}{cc}
\omega_{n} & -\omega_{n} \\
-1 / \omega_{n} & 1 / \omega_{n}
\end{array}\right]\left\{\begin{array}{l}
\xi_{m} \\
\xi_{n}
\end{array}\right\}
\end{aligned}
$$

the line 1 in the structure under 7 degrees frequent earthquake( not listed here due to chapter ).Fig. 10 and Fig. 11 showed respectively the displacement envelope graph and interlayer displacement angle under 7 degrees frequent earthquake.

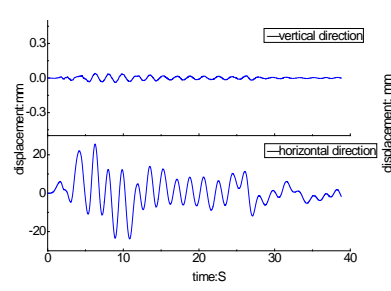

(a)EL Centro wave

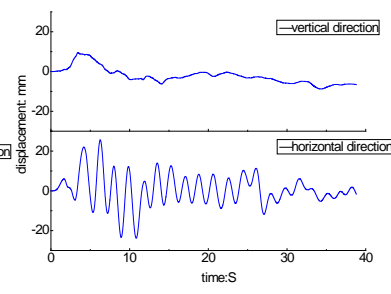

(b)EL Centro wave

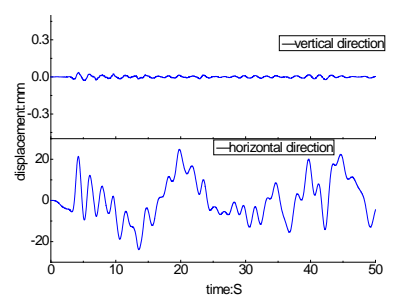

(c) Taft wave

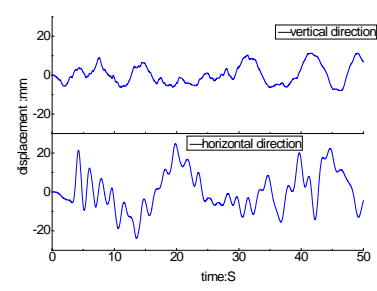

(d) Taft wave

(Horizontal input) (Horizontal + vertical input) (Horizontal input) （Horizontal + vertical input ) Fig. 8.The displacement response time history curve of the top corner in structure (7 degrees frequent earthquake) 


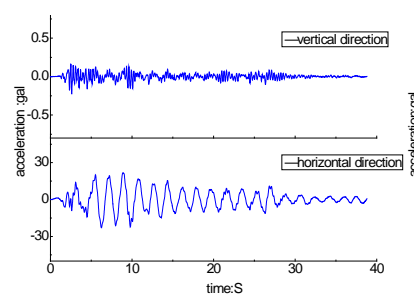

(a) EL Centro wave

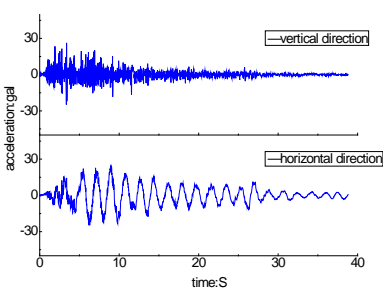

(b)EL Centro wave

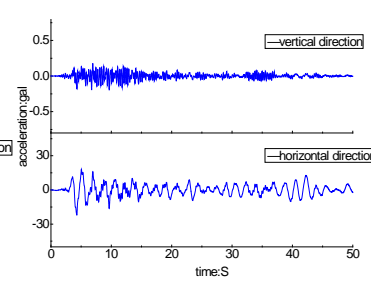

(c) Taft wave

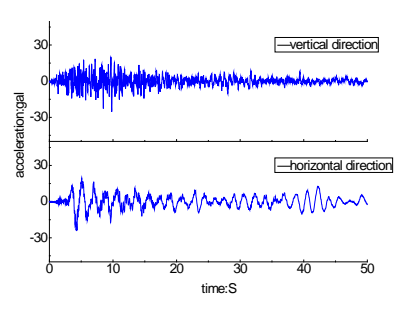

(d) Taft wave

( Horizontal input) (Horizontal + vertical input)

Fig.9 .The acceleration response time history curve of the top corner in structure

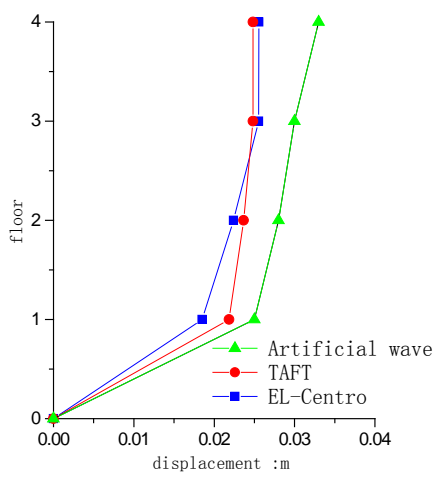

Fig.10.The envelope of floor's horizontal displacement under horizontal earthquake action

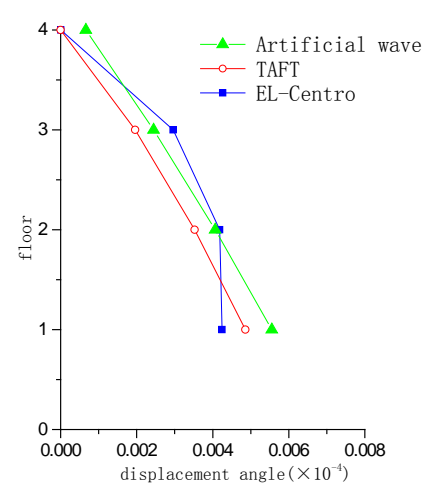

Fig.11.The envelope of interlayer displacement angle under horizontal earthquake action

\section{Conclusion}

In this paper, the seismic response of the concrete transition truss structure was analyzed, and the summary is as follows:

The basic theory equation of mode-superposition response spectrum and dynamic time history analysis was discussed.

According to the actual engineering, the natural vibration period of truss was adjusted. Three sets of seismic wave were imposed: two groups of natural wave and a set of artificial waves. Firstly, the multi-angle analysis of the seismic wave was done to prepare for the inputting of the dynamic time-history analysis. Secondly, nonlinear dynamic time-history analysis of the internal force and node displacement in each truss was don via SAP2000 to get the response of prestressed concrete conversion truss structure under the earthquake action.

\section{Reference}

[1] Zhenhai Guo and Xudong Shi: The Principle and Analysis of The Reinforced Concrete ( Tsinghua university press ,Beijing2003).

[2] Xinrong Tang: Design and Construction of High-rise Building Conversion Layers Structure (China building industry press ,2002)

[3] Guoli Li: The Prestressed Concrete Structure Design Principle (People's traffic press 2000).

[4] Qiang Shen : Prestressed Concrete Truss Transfer Structure Seismic Experimental Research and Theoretical Analysis ( Southeast university civil engineering department , 1996).

[5]Chang Chen: Analysis of SAP2000 structural engineering case (Metallurgical industry press , Beijing2010) 